\title{
Mortality and morbidity among traditionally circumcised Xhosa boys in the Eastern Cape Province, South Africa
}

\author{
SM Mogotlane, Ph. D, Dept. of Health Studies, UNISA \\ JT Ntlangulela, B.A CUR, St. Elizabeth Hospital, Lusikisiki, Eastern Cape \\ BGA Ogunbanjo, M Fam Med, Dept. of Family Medicine \& Primary Health Care, \\ MEDUNSA
}

\section{Abstract}

Male circumcision is one of the oldest traditions observed by many societies. The ritual is performed at specific periods in life with the main purpose of integrating the male child into the society according to cultural norms. Recently, especially in the Eastern Cape, many initiates have died or have had to face life with mutilated genitals following this ritual.

The objective of the study was to explore the causes of morbidity and mortality among traditionally circumcised Xhosa boys in the Eastern Cape.

Methodology: A revelatory case study design was used to obtain information from initiates and traditional surgeons and attendants in the Flagstaff District
Results: From the data collected, restriction of fluid intake, unhealthy surroundings, like, cold and dusty holding rooms and incompetent attendants were cited as factors that contributed to dehydration; wound infection and respiratory infection.

Conclusion: The initiates recommended a collaboration with the Department of Health to ensure that circumcision is performed by knowledgeable persons in appropriate surroundings i.e a clean and warm room with adequate space.

Key terms: Circumcision, morbidity, mortality, initiates, traditional surgeons, traditional attendants.

\section{Introduction}

Male circumcision is one of the rituals practiced world wide. It is the oldest of all the surgical procedures as evidenced by drawings of cave dwellers from the Paleolithic age and the ancient Egyptian tomb of Ankh-Mahor in 2400 B.C respectively which depict or illustrate circumcised men and some Egyptian mummies who were found to have been circumcised (Nasrallah, 1985:593; William and Kapila, 1993: 1231-1236; Ozdemir; 1997:136-139). Currently about a sixth of the world's males are circumcised. The ritual among certain population groups may be performed at birth, during the neonatal period, childhood or early adolescent age. According to Ameh, Sabo and Muhammad (1997:117) in the Islamic religion, circumcision is usually performed between the ages of five (5) and seven (7) years ; while for Muslims it is between the ages of four (4) and thirteen (13) years. In the Jewish community the tradition of circumcision dates back to three thousand and seven hundred (3700) years ago (Shechet and Fried, 1995:1072) from when circumcision was done on the child's eighth day of life by a Mohel as a biblical instruction (mitzvah) (Menahem, 1981:45; William and Kapila, 1993:1231). The Aborigines of
Australia practice circumcision and subincision. The latter is a traditional mutilation of the penis whereby the under surface of the penis including that of the urethra is incised to cause a urethrostomy (Pounder, 1983:227). The ritual is performed to initiate the Aborigine youths into sacred beliefs and rites and into a code of discipline and behaviour maintained by older men in the tribe. The subincision is also used as a site for ritual blood-letting in later initiation ceremonies when sacred blood is drawn from the incision to anoint initiates about to undergo subincision (Pounder, 1983:228).

In South Africa the ritual is integral to many black customs and cultures. In the Xhosa tradition, circumcision is a ritual that is routinely performed to mark the boy's maturity, and it indicates a rite of passage for the adolescent male from boyhood to manhood. The ritual, according to Ngxamingxa (1971:183-184), dates back to 1886. It is usually performed by a traditional surgeon (ingcibi) (who could also be a traditional healer or if not, the surgeon is under the leadership of a traditional healer) to boys aged between 18 and 25 years of age. To perform circumcision, the man uses a sharpened traditional assegai (umdlanga) and would have been 
accorded the status by the community, based on his proven experience with the procedure and process of circumcision. The traditional attendant (ikhankatha) takes on the task of looking after the boys following circumcision, attending to their wounds and ensuring that they eat, exercise, rest and abide by the instructions given, like no drinking of water and no eating of salty foods including meat in the first seven days after circumcision (Mayatula and Mavundla, 1997:16-20). While in the initiation school (ibhoma), the boys are referred to as initiates (abakhwetha) (Mbita, The Star, 11 January, 2000:7).

For the process to be authentic, the procedure followed in the initiation school has to be completely private and women and uncircumcised men are not allowed into the area or informed about the proceedings therein. It is usually performed in the winter months because this is the time believed to be conducive to wound healing. Nowadays, the period is also appropriate and convenient to accommodate those boys that attend school.

In all cases, communities that perform circumcision and/or subincision do not see these as mutilation; but they view them as necessary to enable the male child to adjust and integrate fully into society. It is only after circumcision that the boy is allowed to marry, own property and speak in deaths and thirty six (36) penile mutilations in the Eastern Cape. An unpublished document by Shaw (1994:26) reported that many boys are admitted into the hospital for treatment of complications following traditional circumcision procedure. In December 17, 2000, the newspaper, Sunday Times, reported an incident of 'A rite that went wrong' where a promising sixteen (16) year old standard eight (8) college student died following circumcision. Other newspaper reports, as recent as July, 2001 (Pretoria News, July 16 , 2001 ) indicate the death of seven (7) youths in the North West Province.

The interest to do the study was due to the problems emanating from the practice of traditional circumcision in the Eastern Cape, where boys were often brought to the hospital from the initiation schools presenting with surgical, urological and medical problems which, in some instances resulted in permanent damage to the genitals or death of the affected boys. According to the Flagstaff Health District Circumcision Statistics Report (1996-1998), the total number of boys admitted to hospital from the initiation school in the district was two hundred and four (204). Of these, twenty seven (27) had their glans amputated and another fifteen (15) died following the incidence. See table I below

The above statistics is supported by a report from the Daily

\section{Table 1: Flagstaff district circumcision report 1996-1998}

\begin{tabular}{|l|l|l|l|l|l|}
\hline Sub-district & $\begin{array}{l}\text { No. of initiates } \\
\text { admitted into hospital }\end{array}$ & Diagnosis & Amputation/mutilation & Skin graft & Deaths \\
\hline Bizana & 18 & $\begin{array}{l}\text { Gangrene, sepsis } \\
\text { and assault }\end{array}$ & 4 & Nil & Nil \\
\hline Flagstaff & 37 & “ & 4 & Nil & 4 \\
\hline Lusikisiki & 149 & “ & 19 & 5 & 11 \\
\hline Total & 204 & & 27 & 5 & 15 \\
\hline
\end{tabular}

public gatherings (Meintjes, 1998:67). According to Makupula as cited by Mayatula and Mavundla (1997:1620), the Eastern Cape is mostly affected because the Xhosa community see the practice as mandatory for the boy child to translate from boyhood to manhood.

\section{Problem statement}

In South Africa the problems related to circumcision are not new. Mayatula and Mavundla (1997:16-20) have reported that many boys who underwent traditional circumcision have suffered from shock following pain, haemorrhage and exposure. According to these authors, in 1994, forty two (42) initiates were admitted into Cecilia Makiwane Hospital, Eastern Cape, with sepsis following mass traditional circumcision. Meintjes (1998:67-68) also reported that between $1 / 10 / 1994-1 / 2 / 1995$, there were seven hundred and forty three (743) admissions to hospital, thirty four (34)
Dispatch, 28 July, 1998, which indicates that, many boys face life with mutilated genitals and may encounter problems in marriage including inability to procreate.

Additional statistical information is outlined in the admission records of initiates for the period of June to July 2000 in the three hospitals, Holycross, St.Elizabeth and St. Patrick. This shows a total of forty-two (42) admissions related to botched circumcisions. The diagnoses were mainly sepsis, pneumonia, burns and assault. Of those admitted two (2) initiates $(4,76 \%)$ had penile amputation and six $(6)(14,29 \%)$ had died. (See table 2).

Because circumcision is a custom entrenched in the livelihood of the Xhosa people, it became imperative that the process and procedures be investigated so as to identify the causes of morbidity and mortality among traditionally circumcised boys in the Eastern Cape. 
Table 2: Circumcision statistical report, Flagstaff Health District: June - July 2000

\begin{tabular}{|l|l|l|l|l|}
\hline Magisterial districts & Number of admissions & Reasons for admission & Penile amputation & Deaths \\
\hline $\begin{array}{l}\text { Flagstaff } \\
\text { (Holy Cross Hospital) }\end{array}$ & 4 & Sepsis \& pneumonia & 0 & 2 \\
\hline $\begin{array}{l}\text { Lusikisiki } \\
\text { (St. Elizabeth Hospital) }\end{array}$ & 12 & $\begin{array}{l}\text { Assault, burns, sepsis } \\
\text { \& pneumonia }\end{array}$ & 2 & 3 \\
\hline $\begin{array}{l}\text { Bizana } \\
\text { (St. Patrick Hospital) }\end{array}$ & 26 & $\begin{array}{l}\text { assault, sepsis \& } \\
\text { pneumonia }\end{array}$ & 0 & 1 \\
\hline Total & $\mathbf{4 2}$ & & $\mathbf{2}$ & $\mathbf{6}$ \\
\hline
\end{tabular}

\section{Objective of the study}

The objective of the study was:

1) to explore the causes of morbidity and mortality among traditionally circumcised Xhosa boys.

\section{Methodology}

Setting: The study was conducted in the Flagstaff health district, Eastern Cape, South Africa. The district consists of three magisterial districts, namely, Bizana, Lusikisiki and Flagstaff. Lusikisiki has two (2) district hospitals and fourteen (14) community clinics, Bizana has two (2) district hospitals and eleven (11) clinics, and Flagstaff has one (1) district hospital and seven (7) clinics. In these districts, adolescent males enroll at the initiation schools mainly in the winter months of May and June.

\section{Research design}

This study was exploratory, descriptive and qualitative in nature. A revelatory case study design to document the process of circumcision was used. A case study is an indepth investigation of a contemporary phenomenon within its real-life context and is especially useful when the boundaries between the phenomenon and the context are not evident (Yin, 1994:11). This case study is called revelatory because the information collected provided a rare opportunity to analyse a phenomenon previously inaccessible to scientific investigation (Woods \& Catanzaro, 1988:156). The design was used because of the secrecy around the event which makes obtaining information about circumcision very difficult. In the study the case as well as the unit of analysis was the event or process of circumcision. The embedded cases were the initiates, traditional surgeons, traditional attendants and other older men in the Xhosa community. The case was selected based on its importance in the Xhosa tradition and the fact that the tradition is continuing irrespective of its morbidity and mortality.

Two protocols were used to collect in-depth data from two focus groups of initiates (twelve (12), in each focus group) while still in the initiation school, and five (5) key inform- ants (i.e a traditional surgeon and attendant each from Bizana and Lusikisiki and one elderly man from Flagstaff). Probability sampling was done to include only those who were willing to participate and could provide the needed information. While the participating initiates were met in the initiation school, the traditional surgeons and attendants had been part of the past year's (2001) circumcision activities. The elderly man was identified by the community as someone who knows a lot about the tradition of circumcision amongst the Xhosa group. The one protocol was directed at exploring the initiates' experiences while the other was to explore and describe the actual process and procedure of circumcision by the key informants.

Due to the sensitivity of the issue of circumcision, permission to conduct the study had to be sought from the chief, his herdmen and the community in the health district before the protocols could be tested for trustworthiness. Permission was also obtained from the Provincial Department of Health, Eastern Cape, through the Regional Director and hospital authorities where some of the initiates had been admitted, to be able to gain access to records. Informed consent was obtained from key informants, community leaders, initiates and their families after confidentiality of data to be collected, anonymity and privacy of participants were assured. The two protocols were first open to scrutiny by the chief and his management and then administered to five circumcised men in the Flagstaff district. The men were not part of the interviewees.

As it is taboo for women to discuss circumcision issues, a circumcised male interviewer who had access to the initiation school was engaged to conduct the interviews as well as focus group discussions. The interviewer used a tape recorder and also wrote field notes on some of the aspects discussed and observed. The discussions, in line with the protocols, focused on the health problems related to circumcision. Other sources of data collected included hospital records of initiates admitted to hospitals with complications following the procedure, to determine the possible causes as well as the nature of problems experienced.

\section{Results}

Data collected was analysed by the researchers. Information from the tapes was transcribed, coded and arranged 
into themes. The field notes and discussions with the male interviewer were used to qualify data collected in tapes.

The initiates: Both focus groups indicated that the initiation school was the place where lessons about initiation issues and behaviour were taught and that it was the responsibility of the traditional attendants to deal with all presenting problems. Most initiates (41.66\%) did not inform their parents before enrolling in the initiation school. These simply disappeared from home and were found at the place that hosted the event of circumcision. One of the boys from Lusikisiki said: "I have no father or any male relative. When I felt that I was ready to enroll, I told my mother and I noticed that she was against this as she said the custom is new to her. So, I brought myself to the initiation school". The local people describe this act as 'uku balekela' (this literally means 'to escape into'. The initiate runs away from home to seek temporary refuge in the initiation school).

The initiates were not satisfied with the structures erected for accommodation or as the initiation school. These structures, according to the initiates, did not have proper roofs and the walls were not completely sealed, allowing cold wind to filter through, thereby exposing them to cold weather. The floors were not cemented, and as such, dust and pieces of grass contaminated the wounds; the size of the structure was too small, resulting in overcrowding. It was measured by eight (8) strides for breadth and width to accommodate more than forty (40) boys.

When asked about problems encountered during their stay at the initiation school; the initiates claimed that they were aware of some of the initiates with problems, which they attributed to "evil spirits" and that these usually became worse during their stay at the initiation school or on returning home. The initiates from Lusikisiki reported that one traditional assegai (umdlanga) was used for all of them while those from Bizana had individual surgical blades used. The boys also complained about the surgeon being ruthless during the procedure. All the boys could not remember the surgeon washing his hands at any time before, during or after the procedure. Both focus groups were concerned about pain and infection that usually delayed healing.

The boys reported the age of the initiates as ranging from twelve (12) to twenty (20) years of age.

The initiates reported restrictions in fluid intake and food that is salty including meat. They described their diet as bland consisting of boiled maize or samp.

Key informants: The key informants all agreed that the most suitable time for circumcision was in the winter months of May and June when, it is believed that the climatic conditions were conducive for wound healing and the initiation school building/structure could be constructed on dry ground. They cited eighteen years and older as the correct age for circumcision. The latter was regarded as a good age by key informants in that the boy, according to them has a mature penile erection when stimulated and was ready to enter manhood. A younger age would also be problematic regarding adaptation to the harsh conditions at the initiation school. The amount of the foreskin to be cut was judged by the loose skin that could be pulled over the glans. Heamostasis was maintained by the application of tight animal hide on leaves that served as bandages.

The traditional surgeon, according to the key informants, must be brave to withstand the procedure. This according to them was more important than experience.

The role of the traditional healer was to protect the initiation school and initiates from evil spirits that are believed to lurk around initiation schools. In addition, the traditional healer had the added responsibility of strengthening the traditional surgeon and ridding him of evil spirits and witchcraft which he could pass on to the initiates if not attended to. To do this, the traditional healer makes small scarifications (iintlanga) on the major joints of the surgeon and applies traditional medicine into these. He also provides the surgeon with medicated amulets and strings to tie around the arms, ankles and hip. In addition, both men (traditional surgeon and attendant) must abstain from sexual intercourse throughout the initiation period, as it is believed that their engagement in sex will affect the initiates negatively with the resultant sepsis and delay in wound healing after circumcision. The two men's breath is purified by chewing a herb known as 'isiqunga' to ensure that they do not breathe impurities onto the wounds. The main health problems associated with circumcision as reported by the key informants were pain, and "drop" (layman's term for sexually transmitted diseases) in some initiates which accounted for the sepsis that often occurred. Pain control was with traditional medicines as Western Medicines/analgesics were not acceptable. A herb, umbhangabhanga we hlathi, was used to stop bleeding while wound healing was enhanced by other traditional medicines collectively known as 'izichwe'. It was also believed that eating fatty, sweet and/or salty foods referred to as "inyosi" (bees) and drinking of water before the seventh day after circumcision caused sepsis and these had to be avoided by the initiates.

Elderly community person: His narrative of the process and procedure of circumcision was similar to that of the key informants but did not mention any health problems as a result of the procedure. He, however, expressed concern about the attributes of the 'modern' traditional surgeon, whereupon the traditional surgeon no longer has to be scrutinized by the older men of the clan or community and it could be anyone who has the charm, money and is brave.

The responses of the key informants verified the process and procedure of circumcision as stated in the literature. According to the key informants the old customs and rituals encompassed in circumcision were still upheld with very few variations. The variations included the use of individual surgical blades for circumcising the boys and collaboration with the health personnel in some areas. 


\section{Discussion}

Complications from traditional circumcision are the result of poor operation technique and/or poor care of the surgical wound. From the study, it was clear that the traditional surgeons (iingcibi) were ignorant of the anatomy of the penis based on how the foreskin is chopped rather than excised. One traditional surgeon explained that the operation (circumcision) is done instantly whereupon the initiate has to scream "ndiyindoda" (I am a man) onty once as he chops the foreskin off. In addition, the attendants (amakhankatha) were also ignorant of aseptic technique, the importance of blood circulation and nutrition in wound healing as evidenced by the nature and application of dressings and the restriction of protein rich food. The restriction of fluids together with uncontrolled heamorrhage and pain contributed to dehydration and shock. The team (traditional surgeon and attendant) functioned from the premise that pain and suffering were good for the initiates.

According to Ahmed, Mbibi, Dawan and Kalayi, (1991:113117), trauma, haemorrhage and sepsis are cited as common complications. This notion is supported by William and Kapila (1993:1231-1236) and Menahem (1981:45-48) who have reported on haemorrhage due to laceration or amputation of the glans and/or the penile shaft as well as removal of too much foreskin, denuding the penile shaft. The latter has often resulted in plastic surgery. Other authors, Mayatula and Mavundla (1997:16-20) have also cited consumption of alcohol before and after the operation to dull the pain, as a cause of haemorrhage. From the responses of the key informants as well as those of the initiates in the focus groups there is a potential for the cited complications. The unhygienic manner in which the traditional surgeon performs the procedure without washing hands ever, or washing hands in between boys; the use of a single unwashed blade on all the boys; the dusty and cold holding area in which the boys are kept; the unhygienic wound care practiced by the attendant; the poor nutrition and fluid restriction all contribute to the complications reported in the hospitals records. Gangrene is associated with the use of tight bandages that constrict blood circulation. According to Mayatula and Mavundla (1997) it is the belief of traditional attendants that tight bandages enhance wound healing. The gangrene would, where present, lead to penile amputation. The other concern is the HIV infection, especially from the procedure where the surgeon sometimes uses a single blade for all the initiates.

\section{Conclusions}

The key informants in this study were very protective of the practice. The inclusion of initiates served as a very good buffer as they were objective in their responses. From their responses, the key informants seemed genuine and in as far as they were concerned they were doing a good job, that of maintaining a tradition. It was their feeling too, that if modifications were to be brought in, the ritual would no longer be the same.

As traditional circumcision is a mandatory cultural practice among most black population groups, focus should be on how this practice can be made safe. Serious consultation with communities is required where people can be informed about the changes that have occurred and how these have also affected the environment we live in. The increase in the number of people on earth, the change in the ecosystem, the disease profile as a result of changes in the patterns of living, the food we eat, advances in technology are other factors to be considered. All these have to be communicated to people so that they can understand the potential danger of some practices and see the importance of modifying such traditional customs as circumcision.

Recommendations made included a collaboration with the Department of Health. The initiates strongly supported this notion because they felt that the suffering and risk of contracting HIV/AIDS could be minimized and lives saved (Halperin, 2000:926).

The debate to get the two parties (the traditionalists and the Department of Health) to work together must continue. It must be supported by political commitment through government policies with laws that control the practice so as to ensure sustainability. The introduction of the Tara clamp as recommended by the Department of Health has to be negotiated with the community for it to be accepted. Other aspects of importance include the acceptable training of traditional surgeons and the improvement of the environment where circumcision is done.

The way forward should include education programmes for traditional communities by both the Department of Health and the Department of Arts and Culture with emphasis on social change and its impact on the quality of life.

\section{References}

AHMED A, MBIBI N H, DAWAM D AND KALAYI G D. 1999. Complications of traditional male circumcision. Annals of Tropical Pediatrics. Vol 19(1):113-117

AMEH E A, SABOS Y AND MUHAMMAD I. 1997. Amputation of the penis during traditional circumcision. Tropical Doctor. Vol. 27 (2): 117

DAILY DISPATCH (28/07/98) Code of Ethics for the Eastern Cape "Bush surgeons"

DFPARTMENT OF HEALTH FLAGSTAFF HFALTH DISTRICT. 1996-1998. The statistics of circumcision in Flagstaff District.

HALPERIN, D.T AND BAILEY, R.C. 20M). Male circumcision and HIV Infection. Lancet. Vol.355:926

MAYATULA V AND MAVUNDLA T R. 1997. A review on male circumcision procedures among South African blacks. Curationis. Sep., vol 20 (3): 16-20

MBITA, T. 2000. Safety concerns threaten traditional passage to manhood. Star. January, 11. 
MEINTJIES, G. 1998. Manhood at a price: socio-medical perspectives on Xhosa traditional circumcision. Institute of Social and Economic Research. Rhodes University. Vol. 1:132.

MENAHEM,S. 1981. Complications arising from ritual circumcision: pathogenesis and possible prevention. Israel Journal of Medical Sciences. Vol 17 (1):45-48

NASRALLAH P F. 1985. Circumcision. Pros and cons. Primary Care. Vol 12(4):593-605

NGXAMINGXA A N. 1971. The function of circumcision among the Xhosa-speaking tribes in historical perspective. Man: anthropological essays presented to O.F.Raum. Cape Town, South Africa. C.Struik P.183-204

OZDEMIR E. 1997. Significantly increased complication risks with mass circumcision. British Journal of urology. Vol 80:136-139.

PEETE, F. 2001. Seven initiates dead, 15 others ill in hospital. Pretoria News. P.1.

POUNDER, D.J. 1983. Ritual mutilation. Subincision of the penis among Australian Aborigines. The American Journal of Forensic Medicine and Pathology. Vol. 4(3):227229

SAMPSON, L. A rite that went wrong. Sunday Times. December 17.2000:17

SHAW, V. 1994. The traditional circumcision. Unpublished article.

SHECHET J AND FRIED S M 1995. Traditional Jewish circumcision technique of Bris. American Family Physician. Vol 53(4): 1070-1072

WILLIAMS N AND KAPILA L. 1993. Complications of circumcision. British journal of Surgery. Vol 80 (10):12311236.

WOODS N.F AND CATANZARO, M. 1988. Nursing research. Theory and practice. St. Louis:CV Mosby

YIN, K. 1994. Case study research. Design and methods. $2^{\text {nd }}$ edition. London. SAGE Publications. 